$\mathrm{HE}$

122,2

202

Received 18 July 2021

Revised 20 September 2021 Accepted 20 September 2021

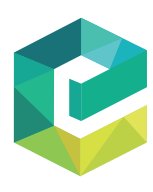

Health Education Vol. 122 No. 2, 2022 pp. 202-216 Emerald Publishing Limited 0965-4283

DOI 10.1108/HE-06-2021-0096

\section{Online multidisciplinary integrated rural healthcare education programs during the COVID-19 pandemic for students from different universities: experiences and guidelines}

\author{
Frances Barraclough
}

Faculty of Medicine and Health, University Centre for Rural Health, The University of Sydney, Sydney, Australia, and

\section{Sabrina Pit}

School of Medicine, University Centre for Rural Health, Western Sydney University, Sydney, Australia;

Faculty of Medicine and Health, University Centre for Rural Health, The University of Sydney, Sydney, Australia and Knowledge Mobilisation Unit, NSW Rural Doctors Network, Newcastle, Australia

\begin{abstract}
Purpose - The COVID-19 pandemic has led to "forced innovation" in the health education industry. Highquality training of the future rural health workforce is crucial to ensure a pipeline of rural health practitioners to meet the needs of rural communities. This paper describes the implementation of an online multidisciplinary teaching program focusing on integrated care and the needs of rural communities.

Design/methodology/approach - A multidisciplinary teaching program was adapted to allow students from various disciplines and universities to learn together during the COVID-19 pandemic. Contemporary issues such as the National Aged Care Advocacy Program for Residential Aged Care COVID-19 Project were explored during the program.

Findings - This case study describes how the program was adopted, how learning needs were met, practical examples (e.g. the Hand Hygiene Advocacy within a Rural School Setting Project), the challenges faced and solutions developed to address these challenges. Guidelines are proposed for remote multidisciplinary learning among health professional students, including those in medical, nursing, pharmacy, dentistry, and allied health disciplines.

Originality/value - The originality of this program centers around students from multiple universities and disciplines and various year levels learning together in a rural area over an extended period of time. Collaboration among universities assists educators in rural areas to achieve critical mass to teach students. In addition it provides experiences and guidance for the work integrated learning sector, rural health workforce practitioners, rural clinical schools, universities, policy makers, and educators who wish to expand rural online multidisciplinary learning.
\end{abstract}

Keywords Allied health, Multidisciplinary, Rural health, COVID-19, Rural medical education, Remote learning, Workforce, Workforce planning, Rural placement, Australia, Videoconferencing

Paper type Case study

(C) Frances Barraclough and Sabrina Pit. Published by Emerald Publishing Limited. This article is published under the Creative Commons Attribution (CC BY 4.0) licence. Anyone may reproduce, distribute, translate and create derivative works of this article (for both commercial and non-commercial purposes), subject to full attribution to the original publication and authors. The full terms of this licence may be seen at http://creativecommons.org/licences/by/4.0/legalcode

Ethical approval: Ethics approval was not sought as the paper was considered a quality assurance project. 
Abbreviations

RCS -

NSW -

$\mathrm{MD}$ -

RHMT -
Rural clinical school

New South Wales

Multidisciplinary

Rural Health Multidisciplinary Training
Rural

healthcare education

programs

\section{Introduction}

Context

There is increasing evidence that a positive rural placement experience for health professionals has a positive impact on practice intention and actual practice uptake in rural areas (Smith, 2018a, b). The Rural Health Multidisciplinary Training (RHMT) program was established in 2016 to expand rural health placements in medicine, allied health, dentistry and nursing. The government allocates placements based on rural classifications (Rural Area (RA) 2-RA5) defined by the Australian Statistical Geography Standard (ASGS), consisting of RA1-RA5 (Major City, Inner Regional, Outer Regional, Remote, Very Remote) (KBC, 2020). The three objectives of the RHMT Program in 2016-2018 are to (1) "provide effective rural training experiences for health students," (2) "maintain well-supported academic networks to enhance the delivery of training to students, junior doctors and specialist trainees in rural, remote and regional areas" and (3) "develop the evidence base for the efficacy of rural training strategies in delivering rural health workforce outcomes." The COVID-19 pandemic has brought about challenges to achieve these three objectives. These challenges have led to forced innovation and the rapid development of online education for health professional students enrolled in undergraduate and postgraduate university programs. The University Center for Rural Health (UCRH) has addressed some of these challenges in delivering a multidisciplinary education program to health professional students who were due to be on rural placements during the COVID-19 pandemic. The program provides an opportunity for students to learn with and from each other, with a focus on the specific needs of rural populations, integrated care and multidisciplinary learning to improve their work-readiness.

This paper aims to:

(1) Describe the experiences of an online multidisciplinary education programs on rural health and integrated care for professional students during COVID-19; and

(2) Based on these experiences, propose guidelines for others wishing to implement online multidisciplinary education.

\section{Theoretical approach}

Interdisciplinary learning strengthens students' ability to work in a team, communicate effectively and provide better patient-centered healthcare solutions (Mackenzie et al., 2007). The program is based on a combination of key theoretical approaches a practicedevelopment approach (McCormack et al., 2009), task-based learning (TBL) (Harden et al., 2000), a mainly student-focused approach (Trigwell et al., 2005) and adaptive expertise (Sockalingam et al., 2016).

Firstly, the program uses a practice-development approach enabling the students to situate themselves within their own practice while taking into account their own and other disciplines, to integrate their learning and develop new knowledge and skills (McCormack et al., 2009). Specifically, the program adopts the practice-development approach where the students learn new knowledge focused on the needs of rural communities and integrated care and develop an understanding of and solutions for COVID-19 within these communities. The program supports and enables students to think beyond their own discipline focused tasks, build deeper relationships with clients and carers, and develop more functional relationships with other disciplines and service providers. Students can also acquire 
$\mathrm{HE}$

122,2

extensive integrated knowledge of the systems of rural health care and social determinants of health. The program allows for creativity and working in teams to solve contemporary issues, such as the COVID-19 outbreak and its effects on rural communities.

Secondly, the program uses TBL, which centers around a set of activities that are related to practice and learning results. The students need to comprehend the multidisciplinary tasks but also the core concepts and mechanisms underlying the tasks (Harden et al., 2000). TBL is used because it has the potential to improve workforce readiness.

Thirdly, the program's teaching approach is both teacher- and student-focused, with the major focus being on students (Trigwell et al., 2005):

(1) The teachers conduct an information transfer of the components of the task to the students (teacher-focused); and

(2) Activities are designed in such a way that the components of the task are taught as a whole, which will lead to conceptual change for the student in relation to rural health, integrated care and other disciplines (student-focused).

Lastly, from the teacher's perspective, an adaptive expertise approach (Sockalingam et al., 2016) is used, whereby the expert is able to distill the complexity of integrated care through continually refining and increasingly describing and discussing patient and system complexity with the students based on their expertise. This assists students in not feeling overwhelmed.

\section{Multidisciplinary education program}

A multidisciplinary education program (the program) has been in place at the UCRH since 2016. Students come from a variety of disciplines and universities across New South Wales (NSW) and Queensland. The program is aimed at students studying health-related degrees, including medicine, nursing, pharmacy, dentistry and allied health (e.g. dietetics, speech therapy, physiotherapy and occupational therapy (Pit et al., 2020).

Students have the opportunity to learn about integrated care within the multidisciplinary program through working with students from other disciplines on joint projects, workshops and academic days and addressing system limitations and developing solutions for complex interplay of patient and system problems.

Curricula for healthcare workers in training do not always promote the attainment of skills and experience in rural communities, primary care settings and integrated care. In many training programs, students learn primary care principles but are then placed in clinical environments often in discipline silos in which it is difficult to implement and practice these principles. This program aims to address this gap and provide an opportunity for students to learn with and from each other, with a focus on the specific needs of rural populations, integrated care and multidisciplinary learning.

The program consists of several structured multidisciplinary programs, including the following:

(1) a weekly full-day face-to-face (or online during COVID-19) workshop on Wednesdays (known as the "Wednesday Program"); and

(2) a weekly 1-h face-to-face student-led patient-based case discussion, which is attended by medical students, nursing, pharmacy and allied health students, UCRH teaching staff and academics and educator clinicians from the local regional hospital and community services (known as the "Friday Student Led Case Discussion").

The students are mostly in their final years of study and are allocated a placement within the Northern Rivers Area of NSW footprint. This footprint includes a variety of small rural towns. Many students are placed in a primary healthcare setting within community organizations such 
as schools or residential aged care facilities. The exception is students studying medical degrees who are predominantly based within the hospital and general practice settings. However, medical students undertake a community research project to become engaged in community-based health and solving inequity issues in rural communities. To address service gaps and community needs, UCRH rural placements sites were selected based on a local rural population needs assessment conducted by the North Coast Primary Health Network (Longman et al., 2020). Students who were on an acute hospital placement were also invited to participate in the program.

\section{COVID-19 opportunities - scaling up}

When the COVID-19 restrictions were introduced, the education program continued and thrived rapidly moving online via the Zoom platform, unexpectedly broadening our capacity to provide multidisciplinary learning opportunities. Two examples of capacity expansion are provided.

Firstly, new university arrangements were established with three universities, allowing an additional 30 undergraduate occupational therapy, nutrition and dietetics, pharmacy and occupational therapy students to participate in the program. Therefore, in addition to students who were already allocated a rural placement within the UCRH, the program was able to provide extra support to partner universities, allowing students who were not allocated an official rural placement to participate in the online program. This enabled these students not only to complete mandatory interprofessional curriculum requirements but also to learn and experience rural health care. COVID-19 has, therefore, incidentally had the benefit of extending the potential for health professional students to be remotely exposed to rural health. Indeed, we postulate that pre-COVID-19, it would not have been thought possible or considered as an option to expand multidisciplinary rural health learning.

Secondly, the Wednesday Program and student-led case discussions could now be recorded on Zoom. This led to sharing the recorded session with two other universities who now use these during their training.

The benefits of the program going online due to COVID-19 were:

(1) An increased capacity to allow students from other disciplines and other universities to participate;

(2) The ability to engage and improved communications with university academics regarding meeting student curriculum requirements;

(3) The ability to record and share lectures across different universities; and

(4) COVID-19 has led to unexpected efficiencies in delivering rural health training.

Table 1 provides an overview of targeted workforce ready skills, learning areas and examples of a typical Online Wednesday Program and online case discussion since COVID-19 started.

\section{COVID-19 adapted real-world rural health projects}

The program had to create new projects that could be developed remotely and presented back to multidisciplinary student groups. Early on COVID-19-related topics were chosen in line with existing rural-based placements sites such as schools and aged care facilities. Two projects are presented here. The first project focused on Hand Hygiene Advocacy within a rural school setting and the second one on National Aged Care Advocacy Program for Residential Aged Care during COVID-19.

To increase student understanding of real-world issues around integrated care such as systems limitations and to learn to think beyond the biomedical model for patients but also to think in terms of real-world solutions, students are exposed practically to current national policy guidelines and directives. For example, the National Aged Care 
$\mathrm{HE}$

122,2

206

Table 1.

Example of content of the Online Wednesday Program and online clinical case discussions
UCRH graduate workforce-ready skills

Rural specific

- Graduates have confidence and skills in working in autonomous environment in rural and remote workplaces

- Graduates are socially accountable

- Graduates are able to improve healthcare equity in rural areas through system and practice change

Healthcare specific

- Graduates are able to provide holistic patient-centred care

- Graduates look after their own well-being (self-care)

General

- Leadership skills

- Innovation ability

- The ability to work in a team

- Ability to work in multidisciplinary settings

Learning areas during the Wednesday Program education sessions

Systems approach

- Focus on an integrated approach between health care and other sectors

- Establish familiarity with local and national programs and services to support health and social needs

- Ability to connect community-based partners, patients and caregivers to local and national programs and services to support their health and social needs

- Emphasizing an integrated knowledge of person-centred, preventative and community-based care, based on the biopsychosocial aspects of disease, systems of care and social determinants of care

Integrated care knowledge and skills

- Skills to construct a comprehensive understanding of individual patients' complex needs and how these can be met within their health and social systems

- In-depth understanding of other disciplines, including referral processes

- Understanding how care is provided in rural areas

- Knowledge of services in small rural towns

- In-depth understanding of early intervention and prevention

- Adaptive expertise is used by the facilitator to encourage students to proactively understand the interaction between patient and system complexity (Sockalingam et al., 2016)

- Management of chronic conditions and improving quality of life for older people

Workforce-ready skills

- Work effectively as a member of a multidisciplinary team

- Work autonomously and self-directed

- Generate new ideas and solutions to complex problems

Examples of topics covered

Multidisciplinary Wednesday Program

National disability insurance scheme, my aged care, national digital health strategies, role of the cancer council, trauma informed care

Friday multidisciplinary clinical case discussion

Management of back pain in the elderly, management of depression in the elderly, management of Type 1 diabetes

Advocacy Program (Department of Health, 2020a), focusing on the implementation of the Aged Care Standards in Residential Aged Care Facilities was used, as well as ideas to implement the recommendations from the recently released Australian Government National Rural Health Commissioner Report (June 2020) on the Improvement of Access, Quality and Distribution of Allied Health Services in Regional, Rural and Remote Australia (Department of Health, 2020b). The content of the sessions included a group session to encourage the students to work in teams to generate novel ideas and solutions based on national policies and directives. Key outcomes were that all students complete 
their university requirements while learning about rural health in a multidisciplinary learning environment.

\section{Hand Hygiene Advocacy within a Rural School Setting project}

For this multidisciplinary project, students were advised that the Department of Education (DOE) has set up a rural consultation group to advise schools on strategies and to implement resources to deal with the COVID-19 outbreak. The DOE has tasked several organizations to provide evidence-based recommendations and resources for schools to adopt now and into the future. Students were asked as a multidisciplinary group, to represent small rural schools in considering the topic of hand hygiene. In line with $T B L$, several tasks and assessments were developed.

Firstly, students were asked to produce a report for the department, based on current evidence as well as their experience of placement within the school environment, to guide approaches to hand hygiene and reducing rates of infection, considering:

(1) Gaps in the school community's knowledge;

(2) Strategies to implement long term;

(3) Identification of international or national guidelines, policies and procedures; and

(4) Any resources or capital works that may be required.

A formative assessment task involved a 500 -word summary report, including key priorities. The students presented the project back to a larger group of students from other disciplines and had to seek feedback to further refine the project. This was concluded with the compilation of the group suggestions into a 500-word reflection of the task.

Secondly, students were tasked to work together in a multidisciplinary team to develop a hand hygiene program, including resources for their placement site (small rural school) that could be adopted nationally. They were asked to (1) identify the target population such as a classroom, a specific age group, teaching staff, volunteers or parents/carers for the home environment; (2) apply and incorporate the five steps of hand hygiene within the chosen setting. A similar formative assessment task as above was developed, including an online presentation of the resources developed, incorporating feedback from the MD online group and including the group suggestions into a 500-word reflection of the task.

\section{National Aged Care Advocacy Program for Residential Aged Care COVID-19 project}

For this MD project, initially, a teacher-focused approach was used to ensure information transfer. Students were taught about the National Aged Care Advocacy Program for Residential Aged Care to ensure they understood the mechanisms and concepts underlying the learning task. Students were advised that the Federal Government Budget funded several initiatives to help aged care providers to:

(1) Adapt to the proposed new aged care standards;

(2) Improve palliative care in residential aged care;

(3) Support aged care capital works in rural and regional Australia;

(4) Develop technological solutions for people living with dementia; and

(5) Encourage healthy aging and improve the mental health of older people.

Students were informed that as part of the budget, they could apply for a national grant to establish a consultancy service to support residential aged care facilities to implement the new aged care standards. Several tasks and assessments were developed.

\section{Rural healthcare education programs}


$\mathrm{HE}$

122,2

\section{8}

Firstly, students were told that the program should assist aged care facilities to understand and apply practical person-centered care and provide examples of how to do this. The grant money could be used to deliver education sessions to aged care providers promoting the new standards. Students were asked to design in a multidisciplinary team a program and resources and present them back to a wider multidisciplinary student group for input. The formative assessment took place by incorporating the group suggestions into a 500-word reflection of the task.

Secondly, similar projects, tasks and assessments were conducted based on establishing a consultancy service to (1) improve palliative care in residential aged care and (2) support aged care capital works in rural and regional Australia. The latter is particularly significant, because students are often not taught about capital works and the influence this can have on rural communities and future service delivery.

Thirdly, given the increased difficulties during the COVID-19 pandemic for older people and the opportunities that digital solutions provide (Fisk et al., 2020), students were also asked as part of the budget and in a multidisciplinary team to apply for a national grant to establish a consultancy service to develop technological solutions for people living with dementia.

Lastly, due to increased mental health problems due to COVID-19 (Fisk et al., 2020), students were asked as part of the budget to apply for a national grant to establish a consultancy service to encourage healthy ageing and improve the mental health of older people. The task assist students in a conceptual change about other disciplines, systems change and integrated care.

\section{Patient-based clinical case discussion during COVID-19: social work and mental health}

A social work student on rural placement was invited to deliver a 30-min presentation to their fellow students. The presentation focused on the scope of social work practice within a rural mental health setting and illustrated appropriate social work assessments and interventions. This was also an opportunity to promote the potential outcomes for people at risk, when a strengths-based and person-centered approach is applied. This opportunity gave the student the experience of collaborating with students across medical and allied health disciplines and extending their knowledge of allied health care beyond the scope of social work. However, it also shows for example medical students the knowledge that other disciplines bring to the table.

\section{Program impact}

As part of quality assurance activities to ensure learning objectives are met and continuous improvement of the program occurs, students are asked to reflect on their UCRH placements. Students comment on improved multidisciplinary learning, increased understanding of other professions, health systems and rural health inequity.

The program aims to increase social accountability and a positive attitude toward working with disadvantaged rural populations. Students have gained a deeper understanding of system limitations and practices within medical and allied health spaces. Students develop confidence in navigating health systems and service delivery. They also improve their capacity to identify and support those who are marginalized and at risk of poorer health outcomes.

Upscaling of the program has occurred, signaling further recognition of the importance of the program.

Firstly, discussions are occurring with urban clinical educators who are considering the potential expansion of the multidisciplinary student-led patient-based clinical case discussions into urban areas, recognizing the collective wisdom of the multidisciplinary team. It is unlikely that this intention would have crystallized without the expansion of online learning due to the COVID-19 pandemic as the webinars were previously not recorded, and hence, knowledge translation did not occur as rapidly. Secondly, several students have expressed the wish to continue to participate in the multidisciplinary learning sessions after completion of their rural 
placements. This has resulted in UCRHalumni now having the opportunity to stay on the email list to allow them to partake in further online multidisciplinary activities.

The program allows for learning from other disciplines and increased understanding of each other's role as students from different disciplines teach other students through the lens of their own professions. This is important to break down current silos in health service delivery and to improve multidisciplinary team work when entering the workforce. This learning complements students' acute care placements. The Zoom platform allows for a flexible mode of learning of workshops and case discussions.

The program, through providing academic support, also assists students to feel part of a community. This is important as research has demonstrated that social isolation during a rural clinical placement is common and reduces rural career intent (Isaac et al., 2018) and is associated with reduced well-being on rural placements, while academic support contributes to student well-being (Saikal et al., 2020). While social isolation has increased during COVID19, students reported feeling connected. The importance of online debriefing at the start of each Wednesday Program among the students proved to play an important role to feel connected so that they can freely discuss the high and lows of their online placements and any challenges they were facing and find potential solutions together.

Lastly, the program aims to make students more work-ready to assist them in their future careers as the setup of integrating different professions in a safe environment allows for a unique opportunity to individually seek help across the professional spectrum and ultimately trial their future career's work in regard to multidisciplinary work environment.

\section{Challenges}

The challenges for the educators when establishing the program online were:

(1) Knowing in advance the audience and who the participants and disciplines would be for each session, as this changes weekly;

(2) The educators had to learn about the Zoom platform;

(3) There were interoperability and policy differences between organizations. Not all organizations had access and were able to use Zoom. For example, the state-based NSW health policy does not allow staff to use Zoom due to privacy concerns, whereas many universities use Zoom as their main online platform. This led to reduced communication abilities between the hospital environment, universities and students during the training program;

(4) It was felt that breakout sessions were hard to manage without administrative support and that information technology (IT) support was needed to ensure high quality online education; and

(5) Partnership agreements and engagement agreements.

Table 2 list some examples of communication methods that were implemented to overcome these challenges that can be used by other programs. For example, challenges were overcome by establishing an online registration system for each of the sessions. This allowed the presenter to know the disciplines and target groups so that the program could be tailored to the needs of the students. An additional benefit was that the organization (the $\mathrm{UCRH}$ ) now has a record of participants for monitoring purposes. Zoom sessions were accessed securely via passwords. It is recommended for breakout sessions to have an admin support to assist in managing the break out groups and monitor when participants have technical difficulties that need to be sorted in real time so that the educator can concentrate on the learning.

\section{Rural healthcare education programs}


$\mathrm{HE}$

122,2

\section{0}

Table 2.

Examples of communication methods used to increase multidisciplinary learning during COVID-19.
Student-focused content of the program

- Student presentations, examples of remote placement outcomes, including the application of telehealth

- Participation on the Zoom platform allowed presentations from organisations such as the Australian Digital Health Agency informing students about new and existing digital health strategies

- Multidisciplinary patient-based student-led case discussions

- Multidisciplinary student debriefing sessions to allow students to discuss challenges in a safe space and provide solutions to each other

- Shared case studies to enhance the students' application of graduate qualities including creativity, innovation, communication and working as a multidisciplinary team

Rural educator focused

- Structured and ad hoc email communications with urban and rural educators

- An online registration process for weekly sessions of health professional student attendees

- Students complete a reflexive formative assessment to identify what they have learnt and to assist the educator to continuously improve the program

- University educators have and are invited to participate in and lead components of the program

Organizational level

- Partnership agreements and engagement agreements with multiple universities

- After the COVID-19 restrictions have been lifted, it is intended that the program will still be offered both face-to-face and via Zoom to allow students from other universities or students who are on a placement in a rural location away from the UCRH to still be able to access the program

- The program will be promoted with other universities

While not implemented at this stage due to time constraints when transforming the program to online delivery, it is envisaged that in the future, student projects will be used to develop grant applications to improve rural health care, such as the grants that were developed for aged care.

\section{Proposed guidelines for developing and implementing a multidisciplinary online learning environment}

An online learning environment allows rural students to be engaged and participate and learn from the knowledge and experiences of other disciplines while being remote. An integrative literature review (Moehead et al., 2020) identified key factors that most likely create an effective online dementia learning environment (Table 3). These factors align with the principles of the practice-development approach in fostering collaboration, inclusion and participation. The program culture allows students to flourish and creates opportunities for active learning and creativity. The program utilizes skilled facilitation through adaptive expertise to direct learning to contemporary issues relevant to the current environment and the needs of a variety of disciplines and rural populations. Therefore, these key factors have been translated and applied to the online multidisciplinary learning environment to assist practitioners when designing online multidisciplinary training courses and to increase workforce readiness among health professional students. Extra factors for consideration were identified based on the practical learnings from the authors, including multidisciplinary learning, good facilitation skills, cyber security, organizational support structures, strong partnerships and the health needs of the community.

\section{Discussion}

This paper described the experiences and upscaling of an online multidisciplinary education program on rural health and integrated care for health professional students during the COVID-19 pandemic, and guidance for others wishing to implement online multidisciplinary education. 
Factors $^{1}$

1. Self-directed/self-paced learning ${ }^{1}$

2. Individualized, based on learner's profile and background $^{1}$

3. Interactive $e^{1}$

4. Multimodal ${ }^{1}$

5. Flexibility ${ }^{1}$

6. Accessible ${ }^{1}$

7. Consistency of information, repetition, and reinforcement ${ }^{1}$

8. Cost-effective and good value for investment both for the learner and system ${ }^{1}$

9. Measures using questionnaires/feedback/ surveys of satisfaction ${ }^{1}$

10. Provides equitable engagement ${ }^{1}$

11. Access to the lecturer who facilitates the program $^{1}$

12. Nurtures critical thinking, reflection and applicability $^{1}$
Guidelines

- Students are self-directed through completing and leading multidisciplinary case discussions at their own pace and within set timeframes

- Students choose their own integrated care topics and develop and complete multidisciplinary team-based projects at their own pace within a set timeframe

- Students present patient-based student-led case discussions from the perspective of their own discipline to students from other disciplines

- An online collaboration platform allows the multidisciplinary education program to be interactive. Students can ask questions or use the chat functions

- Students read various types of resources, watch videos, attend online meetings and write reflections on their own work based on other students' feedback

- Students pick a topic that interests them to increase engagement

- Students can jump into real-time multidisciplinary learning sessions or watch the recordings later

- Students can participate no matter where they are located

- Learning is repeated and reinforced through the following processes: (1) Students are informed about national policies or policy directives (informationtransfer), (2) students are asked to complete a project in relation to the national policies or directives, (3) students present their project back to other students and receive feedback, (4) students incorporate feedback from their peers and write a 500 -word reflection on their learnings

- The online program allows for increased efficiencies. Consider new partnerships so that the program can be expanded to other rural or urban areas and promote multidisciplinary learning at new universities

- At the end of their placement students complete a survey that will assist in further improving the program

- Identify existing data sources to ensure formal feedback about the education program from internal and external sources

- Identify informal feedback from students, peers, university partners and the community partners about the program

Example: Student placement quality surveys, peer observation, ad hoc feedback and internal sources such as the Australian Rural Health Education Network Survey

- Students from anywhere can participate

- An academic lecturer facilitates the program. Students can access the lecturer to ask questions online, email and face-to-face

- Use real-world applications to allow critical thinking about multidisciplinary learning and reflect on the effect on (rural) communities

Example: The School Hand Hygiene Project
Rural

healthcare education

programs 
$\mathrm{HE}$

122,2

15. Multidisciplinary expertise

16. Multidisciplinary learning

16. Good facilitation skills

17. Cyber security

18. Organizational support structures

19. Strong partnerships

20. Health needs of the community

Table 3.

Source(s): ${ }^{1}$ Moehead et al. (2020)
Guidelines

- Debrief sessions and multidisciplinary project teambased learning creates a sense of a learning community among students from different disciplines

- Projects are marked on application to (rural) practice and are based on real-world problems. This assists students to think of system-based as well as individual patientlevel solutions

- Community partners join online sessions to provide realworld context

Example, the impact of COVID-19 on older people and social isolation

- Multidisciplinary facilitators require in-depth knowledge of a wide range of disciplines and health systems to allow students to communicate across various disciplines and understand integrated care solutions

- The expert has adaptive expertise, whereby the expert is able to distill the complexity of integrated care through continually refining and increasingly sharing patient and system complexity with the students based on their expertise

- Students identify the top three health priority issues in an area based on local needs assessments

- Students identify which interventions are implemented in their placements to improve the priority health issues

- Multidisciplinary facilitators need to have good facilitation skills

- Online meetings are recorded in accordance with university policies

- Recordings are saved to a local drive, not a USB or external hard drive, which is nominated in the online platform recording settings

- The local drive is encrypted. The recording is moved to an approved data storage platform and deleted from the local drive

- Strong administrative and IT support structures are in place to ensure seamless integration of online education

- Have strong partnerships with a variety of communitybased organizations

- Have strong partnerships with clinicians from multiple disciplines

- Have strong partnerships with multiple universities

- Provide resources on the health needs of the community

- Ensure students share their knowledge and skills to solve the community needs across disciplines

The program included the following features previously identified for improving online education (Moehead et al., 2020): self-directed/self-paced learning, individualized approach, based on learner's profile and background, interactive, multimodal, flexibility, accessible, consistency of information/repetition/reinforcement, cost-effective and good value for investment both for the learner and the system, measures using questionnaires/feedback/surveys of satisfaction, equitable engagement, facilitated/access to instructor/mentored, nurtures critical thinking/ reflection and applicability, establishment of a learning community and the ability for translation into practice. Other factors identified as important were multidisciplinary expertise, 
multidisciplinary learning, good facilitation skills, cyber security, organizational support structures, strong partnerships and meeting the health needs of the community. We propose that programs could use these features as a guide when developing their own courses.

To our knowledge, there is limited information currently available about multidisciplinary rural health learning online. Yet, understanding this form of learning is crucial to inform the development and training of the future rural health professional workforce so that individuals are comfortable to work in multidisciplinary settings and to safeguard a pipeline of rural health professionals to meet rural communities' needs. Salter et al. (2020) described how they changed rural-based placements to online due to the COVID-19 pandemic and concluded that their placements were responsive, individualized and supported by strong partnerships. Similarly, for our program, partnerships are key to multidisciplinary education, especially because we need to deal with multiple disciplines, multiple universities and a wide variety of community-based organizations.

Because of the COVID-19 pandemic, we will need to increase the delivery of online learning to ensure sustainability of learning for students. Border restrictions, other movement restrictions, placement cancellations in aged facilities and rural schools, school closures and family commitments such as children not being able to go to school or daycare have severely impacted academics and student' ability to be physically present. This means that students need to have a choice of learning online, independent of time or location, and new solutions need to be offered during disasters. Indeed, other disasters such as bush-fires, flooding and drought also need to be considered when designing future rural placements. Rural Australia will continue to experience natural disasters and emergencies, which will have a continued impact on rural health education and service delivery (NSW RDN, 2021). We have demonstrated that it is possible to continue to offer multidisciplinary learning through a pandemic, and that this form of learning can be applied during other national disasters as well.

Humphreys et al. (2018) conducted an evaluation of the university departments of rural health networks across Australia and found that cross-cultural, interprofessional, and simulation training were available across all departments. In addition, it is important to note that a 2020 evaluation of the RHMT Program recommended an increase placements in rural, remote and very remote locations (RA3-5) because $73 \%$ of long-term medical rural placements currently take place in regional areas (RA2), as do $56 \%$ of allied health and nursing placements and $80 \%$ of dentistry placements. Therefore, it is recommended to increase rural placements in more rural and remote regions (KBC, 2020). Our learnings have demonstrated that upscaling and expanding rural placements to more rural areas while still supporting the students is possible.

TBL (Harden et al., 2000) forms an important element of the program to allow students to apply and share their discipline knowledge with other students from other disciplines pertaining to the rural setting and integrated care. Adaptive expertise plays a critical role in multidisciplinary education programs as it encourages students to increase their understanding of the interplay between system and patient complexity (Sockalingam et al.,2016) while learning to solve complex problems. The experts increasingly share their knowledge and expertise with the students as students become more comfortable and experienced. We also believe that a practice-development approach is ideal in this learning environment to increase understanding and skills in rural health and integrated care, and could be embedded in the curricula for our future health workforce. This will assist in the development of more work-ready students.

\section{Limitations}

It is acknowledged that an official evaluation needs to be conducted to measure the sentiment among all students and key stakeholders, but our informal and initial quality assurance feedback cycles demonstrate promising results. Formal evaluations are underway to further improve the program. 
$\mathrm{HE}$

122,2

214

\section{Implications}

The main implication is that our learnings and the program can be translated to other rural areas to increase multidisciplinary learning among students from multiple universities, different disciplines, and year levels. Collaboration between universities assist rural areas in achieving critical mass to teach students. A rural multidisciplinary online education program can assist in reducing some of the perceived barriers to uptake of rural practice, including lack of knowledge around rural training, limited research opportunities, fear of the unknown and a limited rural training pipeline (Bailey and Pit, 2020). For example, the NSW Rural Doctors Network can provide online education sessions during the program about current and future rural workforce-funded opportunities for students attending online education sessions. Through the program, the students also learn that they can easily undertake (research) projects remotely and away from an urban setting and become familiar with rural communities.

The independent Review into Regional Rural and Remote Education (Halsey, 2018, in $\mathrm{KBC}$, 2020) recommended that regional university centers be created to provide tertiary students based in rural areas online education access and support so that they can complete their studies while remaining in their rural communities. Our program can also assist those students to learn remotely about multidisciplinary rural health training, regardless of their location. Our program can also support the establishment of new student placements within community settings in other small rural towns. We argue that multidisciplinary learning should also be embedded more visibly in university curricula. High-quality multidisciplinary education can still be maintained with the use of online technology.

\section{Conclusion}

This paper has provided insight and potential guidelines for the work-integrated learning sector, rural health workforce practitioners, rural clinical schools, universities, policy-makers, and educators who wish to increase rural online multidisciplinary learning and integrated care for tertiary health professional students.

\section{References}

Bailey, J. and Pit, S.W. (2020), "Medical students on long-term rural clinical placements and their perceptions of urban and rural internships: a qualitative study", BMC Medical Education, Vol. 20 No. 188, doi: 10.1186/s12909-020-02103-7.

Department of Health (2020a), "National aged care advocacy framework", available at: https://www. health.gov.au/resources/publications/national-aged-care-advocacy-framework (accessed 6 November 2020).

Department of Health (2020b), "Report for the Minister for Regional Health, Regional Communications and Local Government on the Improvement of Access, Quality and Distribution of Allied Health Services in Regional, Rural and Remote Australia”, June 2020, available at: https:/www1.health. gov.au/internet/main/publishing.nsf/Content/2922D6D8BBCE122FCA2581D30076D09A/\$File/ NationalRuralHealthCommissioner'sAlliedHealthReporttotheMinisterJune2020.pdf (accessed 6 November 2020).

Fisk, M., Livingstone, A. and Pit, S.W. (2020), "Telehealth in the context of COVID-19: changing perspectives in Australia, the United Kingdom and the United States", Journal of Medical Internet Research, Vol. 22 No. 6, e19264, doi: 10.2196/19264.

Halsey, J. (2018), "Independent review of regional, rural and remote education”, (2020), in Kristine Battye Consulting (KBC) (Ed.), Independent Evaluation of the Rural Health Multidisciplinary Training Program Final Report to the Commonwealth Department of Health May 2020, 
Australian Government, Department of Education and Training, Canberra, available at: https:// www1.health.gov.au/internet/main/publishing.nsf/Content/rural-health-rhmt-evaluation (accessed 6 November 2020).

Harden, R., Crosbt, J., David, M., Howie, P. and Struthers, A. (2000), "Task-based learning: the answer to integration and problem-based learning in the clinical years”, Medical Education, Vol. 34, pp. 391-397.

Humphreys, J., Lyle, D. and Barlow, V. (2018), "University Departments of Rural Health: is a national network of multidisciplinary academic departments in Australia making a difference?", Rural and Remote Health, Vol. 18 No. 1, p. 4315, doi: 10.22605/RRH4315.

Isaac, V., Pit, S.W. and McLachlan, C.S. (2018), "Self-efficacy reduces the impact of social isolation on medical student's rural career intent”, BMC Medical Education, Vol. 18 No. 1, p. 42.

Kristine Battye Consulting (KBC) (2020), "Independent evaluation of the rural health multidisciplinary training program final report to the Commonwealth Department of Health May 2020", available at: https://www1.health.gov.au/internet/main/publishing.nsf/Content/rural-health-rhmtevaluation (accessed 6 November 2020).

Longman, J.M., Barraclough, F.L. and Swain, L.S. (2020), "The benefits and challenges of a rural community-based work-ready placement program for allied health students", Rural and Remote Health, Vol. 20, p. 5706, doi: 10.22605/RRH5706.

Mackenzie, A., Craik, C., Tempest, S., Cordingley, K., Buckingham, I. and Hale, S. (2007), "Interprofessional learning in practice: the student experience", British Journal of Occupational Therapy, Vol. 70 No. 8, pp. 358-361, doi: 10.1177/030802260707000806.

McCormack, B., Dewing, J., Breslin, L. and Peelo-Kilroe, L. (2009), "Practice development: realising active learning for sustainable change", Contemporary Nurse, Vol. 32 Nos. 1-2, pp. 92-94, doi: 10.5172/conu.32.1-2.92.

Moehead, A., DeSouza, K., Walsh, K. and Pit, S.W. (2020), "A web-based dementia education program and its application to an Australian web-based dementia care competency and training network: integrative systematic review", Journal of Medical Internet Research, Vol. 22 No. 1, e16808.

NSW Rural Doctors Network (NSW RDN) (2021), "Natural disaster and emergency learnings and recommendations report", available at: https:/www.nswrdn.com.au/site/nder-report (accessed 17 March 2020).

Pit, S.W., Longman, J., Rolfe, M., Smith, L. and McAllister, L. (2020), "Investigation of the validity and reliability of a placement quality survey for measuring rural student work integrated learning placement quality", International Journal of Practice-Based Learning in Health and Social Care, Vol. 8 No. 2, pp. 41-56, doi: 10.18552/ijpblhsc.v8i2.649.

Saikal, A., Pit, S.W. and McCarthy, L. (2020), "Medical student well-being during rural clinical placement: a cross-sectional national survey”, Medical Education, Vol. 54 No. 6, pp. 547-558.

Salter, C.L., Oates, R.K., Swanson, C.H. and Bourke, L.I. (2020), "Working remotely: innovative allied health placements in response to COVID-19", International Journal of Work-Integrated Learning', Vol. 5, pp. 587-600.

Smith, S., Sutton, K., Pit, S.W., Muyuambi, K., Terry, D., Farthing, A., Courtney, C. and Cross, M. (2018a), "Health professional students' rural placement satisfaction and rural practice intentions: a national cross-sectional survey", Australian Journal of Rural Health, Vol. 26 No. 1, pp. 26-32, doi: 10.1111/ajr.12375.

Smith, T., Cross, M., Waller, S., Chambers, H., Farthing, A., Barraclough, F., Pit, S., Muyambi, K. and Anderson, J. (2018b), "Ruralisation of students' horizons: insights into Australian health professional students' rural and remote placements", Journal of Multidisciplinary Healthcare, Vol. 11, pp. 85-97, doi: 10.2147/JMDH.S150623.

Sockalingam, S., Chaudhary, Z.K., Barnett, R., Lazor, J. and Mylopoulos, M. (2020), "Developing a framework of integrated competencies for adaptive expertise in integrated physical and mental health care", Teaching and Learning in Medicine, Vol. 32 No. 2, pp. 159-167. 
$\mathrm{HE}$

122,2

\section{6}

\section{Further reading}

Plochg, T., Ilinca, S. and Noordegraaf, M. (2017), "Beyond integrated care", Journal of Health Services Research and Policy, Vol. 22 No. 3, pp. 195-197.

\section{Corresponding author}

Frances Barraclough can be contacted at: frances.barraclough@sydney.edu.au

For instructions on how to order reprints of this article, please visit our website: www.emeraldgrouppublishing.com/licensing/reprints.htm Or contact us for further details: permissions@emeraldinsight.com 